\title{
Competition with Variety Seeking and Habitual Consumption: Price Commitment or Quality Commitment?
}

\author{
Liyang Xiong, ${ }^{1}$ Guan Liu, ${ }^{1}$ and Shi Jiang ${ }^{2}$ \\ ${ }^{1}$ School of Management, Department of Business Administration, Jinan University, Guangzhou 510632, China \\ ${ }^{2}$ Network and Educational Technology Center, Jinan University, Guangzhou 510632, China \\ Correspondence should be addressed to Liyang Xiong; xiongliyang2015@163.com
}

Received 21 September 2016; Accepted 28 November 2016; Published 6 March 2017

Academic Editor: Aimé Lay-Ekuakille

Copyright (c) 2017 Liyang Xiong et al. This is an open access article distributed under the Creative Commons Attribution License, which permits unrestricted use, distribution, and reproduction in any medium, provided the original work is properly cited.

\begin{abstract}
This paper investigates price and quality competition in a market where consumers seek variety and habit formation. Variety seeking is modeled as a decrease in the willingness to pay for product purchased on the previous occasion while habitual consumption may increase future marginal utility. We compare two competing strategies: price commitment and quality commitment. With a three-stage Hotelling-type model, we show that variety seeking intensifies while habitual consumption softens the competition. With price commitment, firms supply lower quality levels in period 1 and higher quality levels in period 2, while, with quality commitment, firms charge higher prices in period 1 and lower prices in period 2. However, the habitual consumption brings the opposite effect. In addition, with quality commitment variety seeking leads to a lower profit and a higher consumer surplus, while habitual consumption leads to the opposite results. On the other side, with price commitment these behaviors have no effect on the consumer surplus, although they still lower down the firm profits. Finally, we also identify conditions under which one strategy outperforms the other.
\end{abstract}

\section{Introduction}

Future consumption could be influenced by present purchase experience in two important ways: variety seeking and habitual consumption. Variety seeking is the tendency of consumers to seek diversity in their choices of services or goods over time [1]: consumers may get satiated when purchasing the same item again. For example, people would usually avoid eating the exact same meal in the exact same restaurant every day, and most people would not trip to Tokyo if they had traveled to Tokyo the previous year. Instead, habitation consumption contributes to habit formation and, therefore, increases future marginal utility. Luxury goods, technological devices, and narcotics are examples of habit-forming goods.

In psychology, both habit formation and satiation have been studied and observed in animals and humans $[2,3]$. Previous literature has identified a number of psychological processes leading to variety seeking tendencies within individuals. Consumers will be less attracted by the repeat purchasing [4], or consumers feel boredom with the choice task which may result in a product-specific decrease in the perceived hedonic value of the previously chosen alternative [5]. However, consumers will repeat purchase to avoid the risk of change in the choice [6], or consumers will obtain higher satisfaction for habitual consumption [7, 8]. Becker [9] argues that both satiation and habit formation are relevant in predicting future utility. Read et al. [10] state that the most important taste change effects are habit formation and satiation.

Relatively few papers have examined optimal firm strategies in the presence of variety seeking consumers (e.g., [11, 12]) or habitual consumption consumers (e.g., [13]). Sajeesh and Raju [11] study the pricing and positioning competition with variety seeking and Wei et al. [12] study the combinatorial impact of variety and brand name value of the competing firms, while Baucells and Sarin [13] consider modification of the discounted utility model that accounts for both satiation and habit formation in intertemporal choice.

Further notice that in practice firms often adjust product prices to gain competition advantage but fix the quality level, as commonly observed in the retailing industry. However, firms may also adjust the product quality level but keep the 
price fixed, a typical example like the upgrade of smart phones. It is unclear to employ which strategy when there exist consumers with variety seeking and inertia in the market. The objective of this paper is then to examine firms' optimal decisions under two competing strategies: price commitment and quality commitment, in the presence of both variety seeking and habitual consumption behavior. In addition, we try to figure out the conditions under which one strategy outperforms the other.

To study the problem, we employ a three-stage Hotelling model across two time periods. Firms locate at the extreme points of the market. As in Wei et al. [12], with quality commitment variety seeking behavior makes firms enhance the quality levels in the second period while with price commitment firms lower down the prices in the second period so as to keep consumers from switching. On the contrary, the habit formation will bring the opposite effect to the firm. It does not affect the consumers surplus when firms choose the price commitment. We further find out when to choose which competing strategy depends on both of the unit transportation cost and the proportion of the variety seeking consumers in the market. Firms will choose the quality commitment rather than price commitment without variety seeking. If the consumers' unit transportation cost is enough larger, the revenue of the firms with price commitment will be decreased more than the increasing quality levels cost of the firms with price commitment with variety seeking. If the unit transportation cost is small enough, the effect of changing price is less than that of changing quality levels. However, the habit formation could not change these tendencies.

The rest of this paper is organized as follows. The next section reviews the related work. In Section 3, we describe the model. In Section 4, we analyze the firm competition with price commitment and quality commitment, respectively. Section 5 presents the conclusions, limitations, and possible avenues for future research. All the proofs are presented in the appendix.

\section{Literature Review}

This paper relates to studies about variety seeking behavior, the effect of the habit formation, and price and service/quality competition in a duopoly market.

Habit formation and satiation have been studied in psychology for many years. Previous studies think satiation and habit formation capture the basic effects of diminishing sensitivity and adaptation [2, 10]. Diminishing sensitivity is a fundamental property of perception and satisfaction, and adaptation is a fundamental property of living organisms subject to evolutionary forces. Psychologists have also observed that individuals not only increase their preference for a product but also increase their preference for its characteristics from repeated consumption [14].

McAlister and Pessemier [4] and Kahn [1] provide reviews for variety seeking in consumer choices. Recent studies considering the variety seeking behavior on firm decisions include Desai and Trivedi [15], Seetharaman and
Che [16], Sajeesh and Raju [11], and Wei et al. [12]. These papers model variety seeking as negative state dependence for repeat purchasing. Following Sajeesh and Raju [11] and Wei et al. [12], this paper operationalizes variety seeking (satiation) as a relative reduction in the willingness to pay of the previously purchased brand.

Wathieu [17] and Alejandro [18] consider habit formation will increase individuals' preference for their characteristics. Others consider habit formation will increase satisfaction for consumption [13] or dependencies on risk preference that consumers are afraid of loss results of variety seeking [19]. We model the habitual consumption as an increase in the willingness to pay for repetitive purchasing, this setting is different from that where Alejandro [18] models habit formation by assuming that in period 2 the consumers' location will become closer to the firms'.

We build our competition model based on localized model which applies to functionally differentiated products, that is, Hotelling model [20]. Such a model is widely used in marketing literature with variety seeking consumers, to name a few, Klemperer [21], Seetharaman and Che [16], Sajeesh and Raju [11] and Wei et al. [12]. Most of them focus on price competition, with the exception of Sajeesh and Raju [11] for both price and position competition and Wei et al. [12] for both service and price competition. Sajeesh and Raju [11] find that variety seeking can increase product centralization in location equilibrium. Wei et al. [12] find that variety seeking actually increases competition when firms are equally known, while it increases differentiation when one firm is better known as compared to another. Considering vertical competition in a variety seeking market, where preference for variety is captured as a diminishing marginal utility for multiple units of the same firm's products, Zeithammer and Thomadsen [22] find that when qualities are similar, variety seeking softens price competition and increases both prices and profits in equilibrium. On the other hand, if qualities differ enough, price competition is intensified and profits are lowered down. Some empirical research of service competition can be seen in Bubalo and Gaggero [23] and Cheng et al. [24], while, for consumers with habitual consumption, Alejandro [18] claims that habit formation increases product differentiation in location equilibrium. Villas-Boas [25] empirically finds out that firms charge lower price and benefit from having a greater market share today as the loyal consumers in the future.

This paper differs from the previous study in two ways: first, we consider both the variety seeking behavior and the habitual consumption in the same market; second, we discuss the quality and price competition, with the consideration of either price commitment or quality commitment. When the firms choose the price commitment, our results show that variety seeking increases the competition in firms and the habit formation mitigates this effect and firms tend to make equivalent price and quality decisions. Instead, with quality commitment strategy, firms charge lower price in period 2 and higher price in period 1 , and the variety seeking may increase the consumers surplus rather than than the habit formation. 


\section{The Model}

Assume, in duopoly markets, each firm locates at the extremes of a Hotelling line $[0,1]$. Without loss of generality, firm 1 locates at point 0 and firm 2 locates at point 1 . Consumers are uniformly distributed among the line, and we normalize the total number of consumers to 1 in each period. Both of the firms sell their products to consumers over two consecutive periods. Each consumer buys one and only one unit of the product from a firm in each period, and consumers maximize their utility obtained from consumption of products to make their purchasing decision, whose utility obtained from firm $i, i=1,2$, is

$$
U_{i j}(x)=V-p_{i j}+\beta q_{i j}-h_{i}(x),
$$

where $V$ denotes the basic utility from the consumption of products, $p_{i j}$ and $q_{i j}$ stand, respectively, for the price and the quality of firm in period $j, j=1,2, h_{i}(x)$ denotes the traveling cost between the consumer at $x$ and the location of firm $i$; that is, $h_{1}(x)=h x$ and $h_{2}(x)=h(1-x) . h$ is the unit transportation cost (Upender 2013) and $\beta>0$ is the sensitivity of the quality.

At the beginning of the first period, each firm decides its price $p_{i 1}$ ( or $q_{i 1}$ ) simultaneously, and once the prices (or quality levels) are determined they are fixed thereafter. Then firms maximize their profit by choosing the quality levels $q_{i 1}$ (or $\left.p_{i 1}\right)$, whose net profit, respectively, is

$$
\pi_{i j}=P_{i j} d_{i j}-c\left(q_{i j}\right),
$$

where $d_{i j}$ denotes the demand of the firm $i$ in period j. $c\left(q_{i j}\right)=$ $(\alpha / 2) q_{i j}^{2}, \alpha>0$, is the cost as producing a product of quality $q_{i j}$. Then, the consumer who located at $x$ maximizes its utility to choose the products of firm $i$.

At the beginning of the second period, firstly, we made the assumption that some consumers make their purchasing decision independent of the past purchasing experience, in other words, these consumers have no variety seeking behavior or habitual consumption behavior when consuming the same product on consecutive purchase occasions. Then both of the firms will adopt the same strategies as that of last period. Therefore, both firms making the unchanged decisions can get the optimized total two-period profit.

However, rich empirical research and literature certified the existence of satiation and habit formation [2, 4]. Before the discussion, we made the following setting: the number of variety seeking consumers $(\theta)$ is more than that of habitual consumption consumers $(\varphi)$; that is, $0<\varphi<\theta<1$, and $\varphi+\theta<1$. And these $\theta$ and $\varphi$ consumers are also distributed uniformly on the Hotelling line $[0,1]$.

For a fraction $\theta$ of consumers who are variety seeking, their willingness to pay for the product they purchased in period 1 goes down by $k$ in period 2 because of satiation or boredom. Let $k<h$ ensure the marginal consumers are located within the distribution of consumers for all values of $\theta$. Otherwise, the marginal consumers are located at the extremes of the line segment. Equilibrium results presented in this paper hold only when $k<h$. Then a fraction $\varphi$ of consumers, who have habit formation in the market, prefer purchasing the same product as habit formation that can get more satisfaction $l$. All of $\theta, \varphi, k$, and $l$ are exogenous to the model. In this way, variety seeking is modeled as a disutility from the decreasing reserved value instead of a permeant change in consumers' position the same as that of the habit formation. Therefore, in period 2, a variety seeking consumer and a habitual consumption consumer with location $x$ have the utility from consuming the product of firm $i$, respectively:

$$
\begin{aligned}
& U_{i 2}(x)=V-p_{i 2}+\beta q_{i 2}-h_{i}(x)-k \delta(i), \\
& U_{i 2}(x)=V-p_{i 2}+\beta q_{i 2}-h_{i}(x)+l \delta(i),
\end{aligned}
$$

where $\delta(i)=1$ if the consumer purchased product $i$ at period 1 ; otherwise, $\delta(i)=0$.

For the rest $(1-\theta-\varphi)$ consumers, their reservation utility does not change for the repetitive purchasing. Consumers then make their choice based on the utility maximization as in period 1 . Therefore, both of the firms offer the quality $q_{i 2}\left(p_{i 2}\right)$ to maximize their total two-period profit according to the strategies of period 1. In our discussion, we need to define $2 h \alpha>\beta^{2}$ ensuring the existing of equilibrium for all value of $\theta$ and $\varphi$.

\section{Analysis}

This section investigates the equilibrium in duopoly competition. We investigate the competition with price commitment and quality commitment scenarios. The former case indicates that both firms do not change the price while the latter do not change the quality level. We use superscript " $p$ " for price commitment and " $q$ " for quality commitment, separately. Before we assume $2 h \alpha>\beta^{2}$; only in this condition is our discussion meaningful for any $\theta$ and $\varphi$. In the analysis we employ the concept of subgame perfect equilibrium and analyze the decisions of firms and consumers in a reverse order.

4.1. Under Price Commitment. We first consider price commitment, where all firms have the same price in both periods and only adjust the quality level in period 2 .

We start with a benchmark with no variety seeking consumers and no habitual consumption consumers in the market; that is, $\theta=0$ and $\varphi=0$. Both firms and consumers repeat the same decisions in period 2 as in period 1 . The original three-period Hotelling problem is reduced to a two-period duopoly competition model. The equilibrium solutions are illustrated in the following proposition. $p_{i 0}^{p}$ and $q_{i 0}^{p}$ denote the equilibrium solutions, with subscript 0 indicating $\theta=0$ and $\varphi=0$.

Proposition 1. Under price commitment, without variety seeking and habitual consumption, the equilibrium prices and quality decisions are as follows: $p_{10}^{p}=p_{20}^{p}=h$ and $q_{10}^{p}=q_{20}^{p}=$ $\beta / 2 \alpha$.

Under price commitment, Proposition 1 indicates that both firms make the same price and quality decisions when 
there are no variety seeking and habitual consumption consumers in the market. Each firm equally shares the market, that is, $d_{10}^{p}=d_{20}^{p}=1 / 2$. Each firm has the same profit level $\pi_{10}^{p}=\pi_{20}^{p}=h / 2-\beta^{2} / 8 \alpha$. It should be pointed out that this result is the same as in Wei et al. [12] where only variety seeking consumers exist in the market.

When there exist both variety seeking and habit formation consumers in the market, that is, $0<\theta, \varphi<1$, both firms decide price $p_{i}$ at period 0 . Then firms decide the quality levels $q_{i 1}$ at period 1 and make adjustment to $q_{i 2}$ at period 2 . Consumers purchase products based on utility maximization. In period 1, consumers compare the utilities based on (1) and decide which product to buy. The aggregate demand for each firm in period 1 is then

$$
\begin{aligned}
& d_{11}^{p}=\frac{p_{2}-p_{1}+\beta\left(q_{11}-q_{21}\right)+h}{2 h} \\
& d_{21}^{p}=\frac{p_{1}-p_{2}+\beta\left(q_{21}-q_{11}\right)+h}{2 h} .
\end{aligned}
$$

In period $2, \theta$ consumers with variety seeking behavior reduce their willingness to pay for the product which they have purchased in the previous occasion. The utility that consumers obtain from purchasing the same product is then reduced by $k$, as indicated in (3). $\varphi$ consumers with habitual consumption increase their willingness to pay for the product which they have purchased in the previous occasion. The utility that consumers obtain from purchasing the same product is then increased by $l$, as indicated in (4). These negative and positive state dependence cause the demand for firm 1 at period 2 from four types of consumers.

Type 1. Among the consumers who have no variety seeking and habitual consumption, consumers purchase from firm 1 if the utility obtained from the product of firm 1 is larger than that of firm 2. For type 1 consumers, they make their purchasing decisions at period 2 simply based on $V-p_{1}+$ $\beta q_{12}-h x \geq V-p_{2}+\beta q_{22}-h(1-x)$. The number of type 1 consumers purchasing product from firm 1 therefore equals

$$
(1-\theta-\varphi) \frac{p_{2}-p_{1}+\beta\left(q_{12}-q_{22}\right)+h}{2 h} .
$$

Type 2. These are variety seeking consumers who purchased from firm 2 in period 1. Because of satiation with firm 2's product, their willingness to pay for the product of firm 2 goes down by $k$. These consumers change to purchase from firm 1 if $V-p_{1}+\beta q_{12}-h x \geq V-p_{2}+\beta q_{22}-h(1-x)-k$. The fraction of type 2 consumers then equals

$$
\theta \frac{\beta\left(q_{21}-q_{11}\right)-\beta\left(q_{22}-q_{12}\right)+k}{2 h} .
$$

Type 3. Among the variety seeking consumers, those who purchased from firm 1 in period 1 continue to purchase from firm 1 in period 2, although their willingness to pay goes down by $k$ because of satiation. Therefore, this fraction of consumers equals

$$
\theta \frac{p_{2}-p_{1}+\beta\left(q_{12}-q_{22}\right)-k+h}{2 h} .
$$

Type 4. Among the habitual consumption consumers, those who purchased from firm 1 in period 1 have the habit formation, and their willingness to pay goes up by $l$ because of habitation consumption. As both firms are symmetric, these consumers that purchased from firm 1 in period 1 continue to purchase from firm 1 in period 2, Therefore, these consumers equal

$$
\varphi \frac{p_{2}-p_{1}+\beta\left(q_{11}-q_{21}\right)+h}{2 h} .
$$

Adding the four types of demands together, the total demand for firm 1 in period 2 is then

$$
\begin{aligned}
d_{12}^{p}= & (1+\theta-\varphi) \frac{\beta\left(q_{12}-q_{22}\right)}{2 h}+\frac{p_{2}-p_{1}+h}{2 h} \\
& +(\varphi-\theta) \frac{\beta\left(q_{11}-q_{21}\right)}{2 h} .
\end{aligned}
$$

Similarly, the total demand for firm 2 in period 2 is

$$
\begin{aligned}
d_{22}^{p}= & (1+\theta-\varphi) \frac{\beta\left(q_{22}-q_{12}\right)}{2 h}+\frac{p_{1}-p_{2}+h}{2 h} \\
& +(\varphi-\theta) \frac{\beta\left(q_{21}-q_{11}\right)}{2 h}
\end{aligned}
$$

The objective of firm $i$ is then to decide $p_{i}$ in period $0, q_{i 1}$ in period 1 , and $q_{i 2}$ in period 2 so as to maximize the total profit $\pi_{i}^{p}$ in both periods.

$$
\pi_{i}^{p}=\pi_{i 1}^{p}+\pi_{i 2}^{p}=p_{i} \cdot d_{i 1}^{p}-\frac{\alpha}{2} q_{i 1}^{2}+p_{i} \cdot d_{i 2}^{p}-\frac{\alpha}{2} q_{i 2}^{2} .
$$

Working backward, we first consider in period 2 each firm decides their quality levels $\left(q_{i 2}\right)$ to maximize profits $\left(\pi_{i 2}\right)$ in period 2 , given price $\left(p_{i}\right)$ and quality levels in period $1\left(q_{i 1}\right)$ are determined. Then firms chooses $q_{i 1}$ and $p_{i}$ to maximize the profit in period 1 . The equilibrium solutions are summarized in Proposition 2.

Proposition 2. Under price commitment, with variety seeking and habitual consumption, that is, $0<\varphi<\theta<1$, the equilibrium prices and quality decisions are as follows: $p_{1}^{p}=$ $p_{2}^{p}=h, q_{11}^{p}=q_{21}^{p}=((1+\varphi-\theta) / 2 \alpha) \beta$, and $q_{12}^{p}=q_{22}^{p}=$ $((1+\theta-\varphi) / 2 \alpha) \beta$. In addition, average quality level is unchanged $\left(\left(q_{i 1}^{p}+q_{i 2}^{p}\right) / 2=q_{i 0}^{p}, \quad \forall i=1,2\right)$

Proposition 2 reveals that both firms make the same quality and price decisions when the consumers have variety seeking and habitual consumption. This is consistent with the findings in Sajeesh and Raju [11] (as well as in [12]), in which the firms differentiate less in their location (service) decisions and make the same price decisions in the presence of variety seeking consumers. The equilibrium prices are not affected by the variety seeking and habit formation.

We found the variety seeking and the habit formation bring the opposite effect for firm decisions. The habit formation make the firm would not choose too low quality level in period 1 , and the variety seeking makes the firm choose a little 
higher quality level in period 2. However, neither the variety seeking nor the habit formation can affect the average quality and price in both periods.

Proposition 3. Under price commitment, the presence of variety seeking reduces firm profits and does not change the consumers surplus. Although the habitual consumption has no effect on consumers surplus, it reduces the loss results of variety seeking.

Although the presence of variety seeking behavior does not change the price and the average quality level, it increases the quality differentiation in two periods and decreases the total profit of each firm. The latter is because of the convex cost function of quality levels. Intuitively, a firm needs to pay a cost to prevent variety seeking consumer from switching. However, the habitual consumption can decrease the loss results of variety seeking or benefits the firms, as the quality differentiation becomes less. Therefore, a firm also should cultivate the consumers habit to reduce the loss.

4.2. Under Quality Commitment. Then we consider quality commitment, where each firm has the same quality in both periods and only adjusts the price in period 2 . We also start with a benchmark with no variety seeking consumers and no habitual consumption consumers in the market; that is, $\theta=0$ and $\varphi=0$.

Similarly, we start with the case without variety seeking and habitual consumption consumers $(\theta=0, \varphi=0)$. Both firms and consumers will repeat the same decisions in period 2 as in period 1 , and the original three-period Hotelling problem is reduced to a two-period duopoly competition model. The equilibrium solutions are illustrated in the following proposition. $p_{i 0}^{q}$ and $q_{i 0}^{q}$ denote the equilibrium solutions, with subscript 0 indicating $\theta=0$ and $\varphi=0$.

Proposition 4. Under quality commitment, without variety seeking and habitual consumption, the equilibrium prices and quality decisions are as follows: $p_{10}^{q}=p_{20}^{q}=h$ and $q_{10}^{q}=q_{20}^{q}=$ $\beta / 3 \alpha$.

Proposition 4 indicates that both firms also make the same price and quality decisions when there are no variety seeking and habitual consumption consumers in the market. Each firm equally shares the market; that is, $d_{10}^{q}=d_{20}^{q}=1 / 2$. Each firm has the same profit level $\pi_{10}^{q}=\pi_{20}^{q}=h / 2-\beta^{2} / 18 \alpha$.

When there exist variety seeking and habit formation consumers in the market, that is, $0<\theta, \varphi<1$, both firms decide quality level $q_{i}$ at period 0 . Once decided, it is fixed thereafter. Then both firms decide the price $p_{i 1}$ at period 1 and make adjustment to $p_{i 2}$ at period 2. Similarly, in period 1 , firms choose price and quality. Then, the consumers purchase the product that provides them with the highest utility, and then we can get the demand for each firm as

$$
\begin{aligned}
& d_{11}^{q}=\frac{p_{21}-p_{11}+\beta\left(q_{1}-q_{2}\right)+h}{2 h} \\
& d_{21}^{q}=\frac{p_{11}-p_{21}+\beta\left(q_{2}-q_{1}\right)+h}{2 h} .
\end{aligned}
$$

In period 2 , with the existing of $\theta$ consumers with variety seeking and $\varphi$ with habit formation, the demand for firm 1 at period 2 also comes from four types of consumers the same as that situation with price commitment.

Type 1. Among $(1-\theta-\varphi)$ consumers who have no variety seeking and habitual consumption, consumers purchase from firm 1 if the utility obtained from the product of firm 1 is larger than that of firm 2; that is, $V-p_{12}+\beta q_{1}-h x \geq V-p_{22}+$ $\beta q_{2}-h(1-x)$. The number of these consumers equals

$$
(1-\theta-\varphi) \frac{p_{22}-p_{12}+\beta\left(q_{1}-q_{2}\right)+h}{2 h} .
$$

Type 2. These are variety seeking consumers who purchased from firm 2 in period 1. Because of satiation with firm 2's product, their net utility is higher in period 2 by buying from firm 1 . This fraction of type 2 consumers equals

$$
\theta \frac{\left(p_{22}-p_{12}\right)-\left(p_{21}-p_{11}\right)+k}{2 h} .
$$

Type 3. These are variety seeking consumers who purchase from firm 1 in period 1 and continue to purchase from firm 1 in period 2, although their willingness to pay goes down by $k$ because of satiation. These consumers equal

$$
\theta \frac{p_{22}-p_{12}+\beta\left(q_{1}-q_{2}\right)-k+h}{2 h} .
$$

Type 4. The habitation consumption consumers who purchased from firm 1 in period 1 will continue to purchase from firm 1. This happens because for such consumers the willingness to pay has increased for the product from firm 1 in period 2. The fraction of consumers is given by

$$
\varphi \frac{p_{21}-p_{11}+\beta\left(q_{1}-q_{2}\right)+h}{2 h} .
$$

Adding the four types of demands together, the total demand for firm 1 in period 2 is then

$$
\begin{aligned}
d_{12}^{q}= & (1+\theta-\varphi) \frac{p_{22}-p_{12}}{2 h}+\frac{\beta\left(q_{1}-q_{2}\right)+h}{2 h} \\
& +(\varphi-\theta) \frac{p_{21}-p_{11}}{2 h} .
\end{aligned}
$$

Similarly, the total demand for firm 2 in period 2 is

$$
\begin{aligned}
d_{22}^{q}= & (1+\theta-\varphi) \frac{p_{12}-p_{22}}{2 h}+\frac{\beta\left(q_{2}-q_{1}\right)+h}{2 h} \\
& +(\varphi-\theta) \frac{p_{11}-p_{21}}{2 h} .
\end{aligned}
$$

Each firm then decides price and quality levels to maximize its total profit $\pi_{i}^{q}$ over two periods.

$$
\pi_{i}^{q}=\pi_{i 1}^{q}+\pi_{i 2}^{q}=p_{i 1} \cdot d_{i 1}^{q}-\frac{\alpha}{2} q_{i}^{2}+p_{i 2} \cdot d_{i 2}^{q}-\frac{\alpha}{2} q_{i}^{2} .
$$

Working backward, we first consider that each firm decides their price $\left(p_{i 2}\right)$ to maximize profits $\left(\pi_{i 2}^{q}\right)$ in period 2 , 


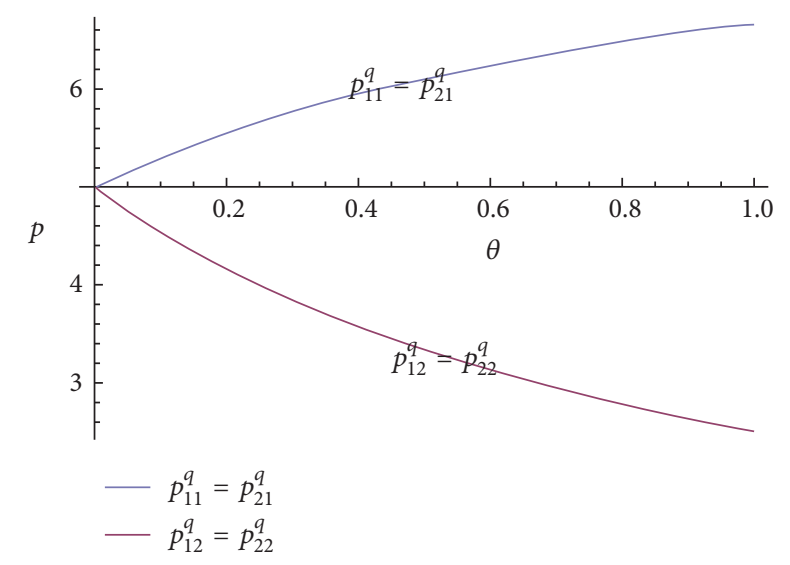

FIGURE $1: h=5, \varphi=0, \alpha=1$, and $\beta=0.8$, prices change with $\theta$.

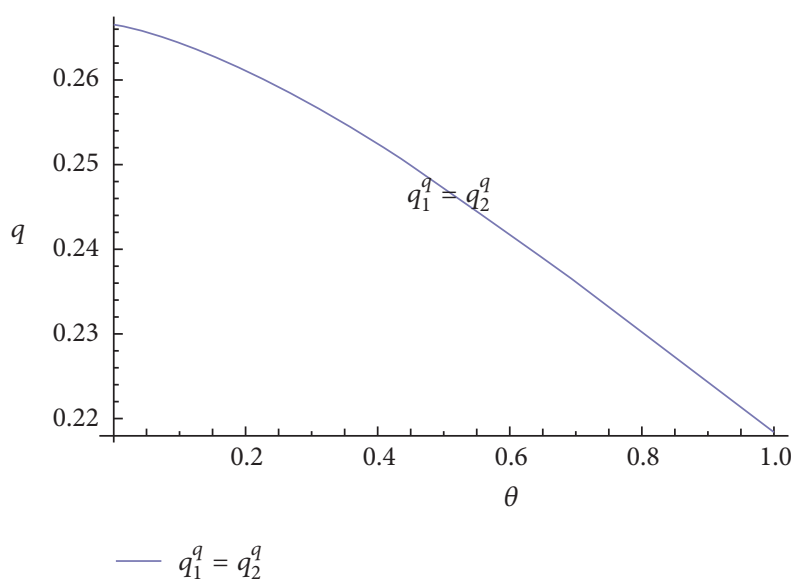

FIGURE 2: $h=5, \varphi=0, \alpha=1$, and $\beta=0.8$, quality levels change with $\theta$.

given that price $\left(p_{i 1}\right)$ and quality levels in period $1\left(q_{i}\right)$ are determined. Then firms chooses $\left(p_{i 1}\right)$ and $\left(q_{i}\right)$ to maximize the profit in period 1 . The equilibrium solutions are summarized in Proposition 4.

Proposition 5. Under quality commitment, with variety seeking and habitual consumption, that is, $0<\theta, \varphi<1$, the equilibrium prices and quality decisions are as follows: $p_{11}^{q}=p_{21}^{q}=$ $((3+5(\theta-\varphi)) / 3(1+\theta-\varphi)) h, p_{12}^{q}=p_{22}^{q}=h /(1+\theta-\varphi)$, and $q_{1}^{q}=q_{2}^{q}=\beta\left[54+105(\theta-\varphi)+41(\theta-\varphi)^{2}-10(\theta-\varphi)^{3}\right] / 6 \alpha(1+$ $\theta-\varphi)\left(27+27(\theta-\varphi)-4(\theta-\varphi)^{2}\right) \cdot p_{i 1}^{q}>p_{i 2}^{q}, \forall i=1$, 2. In addition, the price gap increases with $\theta$ (see Figure 1), and the quality $\left(q_{i}^{q}\right)$ decreased with $\theta$ (see Figure 2 ); however, the habit formation will bring the opposite effect.

Figures 1 and 2 mainly discuss the impact of variety seeking on the price and the quality levels, we assumed that other exogenous variables are constant, and their values do not affect our discussion. As $0<\varphi<\theta<1$, we can easily find the impact of the habitual consumption.
Different from the price commitment, although the quality is committed, the presence of variety seeking behavior changes not only the prices but also the quality levels the same as the habit formation. As the presence of variety seeking behavior, the firm charges lower price in period 2 and higher price in period 1 , and the habit formation also mitigate this effect of the variety seeking.

As in price commitment, the variety seeking and habit formation affect firms pricing decisions of period 2 in a different way. However, the variety seeking also affects firm quality level decisions, as the quality cost function is concave; in consideration of charging lower price in period 2 , firms will supply the lower quality level to save quality cost.

Proposition 6. Under quality commitment, variety seeking behavior increases consumer surplus while it decreases the total profit; on the contrary, the habit formation has the opposite effect.

Differentiating from the price commitment, in quality commitment, consumers can gain more surplus from variety seeking, but the habit formation will hurt the consumer surplus. Although the variety seeking will make the firms decrease the quality cost, they also decrease the average price in both periods and make the firms revenue decrease. For firms, the only way to solve this situation is that the firms need to cultivate the proportion of habitation consumption consumers.

4.3. Comparison of the Price Commitment and the Quality Commitment. When there are no variety seeking consumers in the market, the firm will supply the higher quality levels under the price commitment; therefore, the firm will choose the quality commitment rather than price commitment for cost consideration. However, with variety seeking consumers in the market, how will the firms choose the strategy: price commitment or quality commitment? The following theorem provides an answer.

Theorem 7. In the presence of variety seeking consumers, when $h>1439 \beta^{2} / 300 \alpha$, there exists $0<\theta^{*}<1$ such that $\pi_{i}^{p}=$ $\pi_{i}^{q}, \forall i=1,2$.

(i) For $\theta \in\left(0, \theta^{*}\right)$, the quality commitment is better; otherwise, the price commitment is better (see Figure 3).

When $h<1439 \beta^{2} / 300 \alpha$, there exists $h^{*}<1439 \beta^{2} / 300 \alpha$ and $0<\theta_{0}^{*}<1$ makes $\pi_{i}^{p}=\pi_{i}^{q}, \forall i=1,2$.

(ii) If $0<\theta_{1}^{*}<\theta_{0}^{*}<\theta_{2}^{*}<1$, for $\theta \in\left(\theta_{1}^{*}, \theta_{2}^{*}\right)$, the price commitment will benefit each firm; otherwise, each firm will choose quality commitment (see Figure 4).

(iii) If $h<h^{*}$, the firm profit of quality commitment will always be better (see Figure 5).

Figures 3-5 discuss the impact of variety seeking on profits under the price commitment and the quality commitment. Therefore, we assumed that other exogenous variables are constant, and their values do not affect our discussion only if $h>1439 \beta^{2} / 300 \alpha$ in Figure $3, h^{*}<h<1439 \beta^{2} / 300 \alpha$ in Figure 4, and $h<h^{*}$ in Figure 5. As $0<\varphi<\theta<1$, we can easily find the impact of the habitual consumption. 


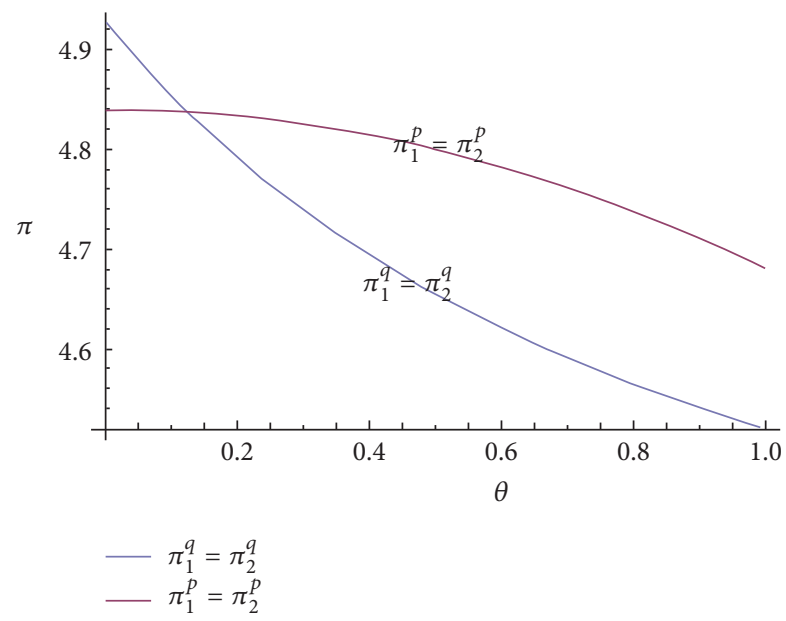

Figure 3: $h=5, \varphi=0, \alpha=1$, and $\beta=0.8$, comparing the profit of quality commitment and the profit of price commitment with variety seeking $\theta$.

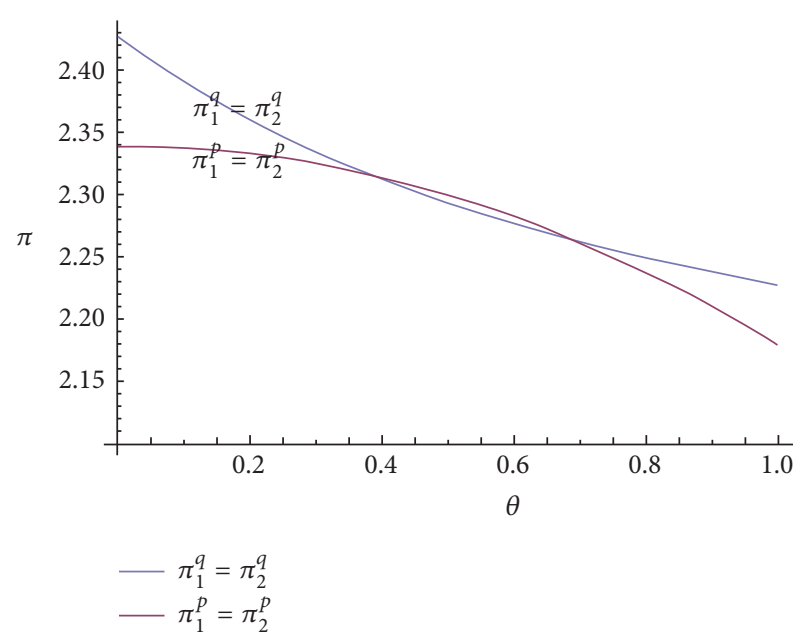

FIgURE $4: h=2.5, \varphi=0, \alpha=1$, and $\beta=0.8$, comparing the profit of quality commitment and the profit of price commitment with variety seeking $\theta$.

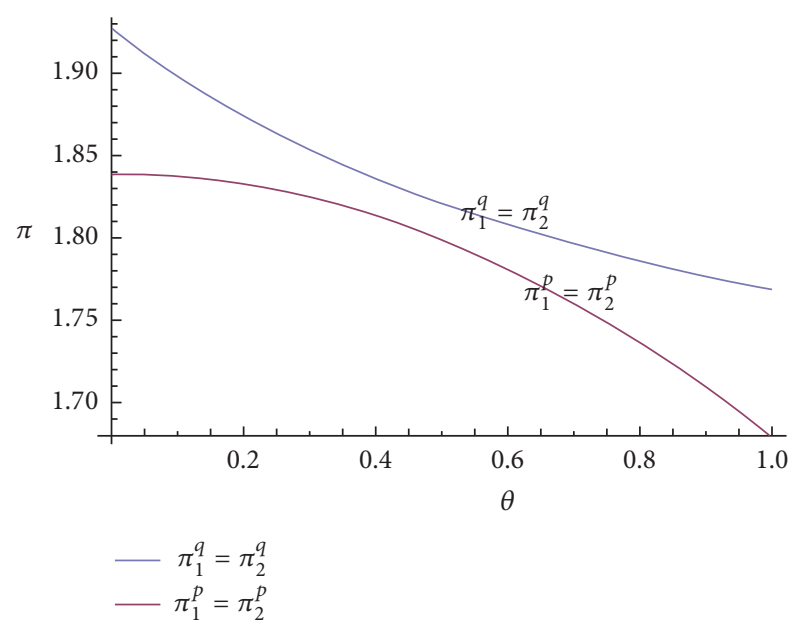

FIgURE 5: $h=2, \varphi=0, \alpha=1$, and $\beta=0.8$, comparing the profit of quality commitment and the profit of price commitment with variety seeking $\theta$.
Although in the two situations (price commitment and quality commitment), with the variety seeking behaviors, the profit of total market decreases, the difference between the two situations is that the loss profit of the former resulted in the increasing cost of quality, and the loss profit of the latter resulted in the decreasing revenue of decreasing average price that is bigger than the saving cost of decreasing quality. Our explanations are as follows. If the unit transportation cost $h$ of the consumers' ideal points to firm is enough larger, when the fraction of variety seeking consumers is large enough, firms that choose price commitment will gain more, and when the fraction of variety seeking consumers is small enough, the quality commitment will be better decision. If the unit transportation cost $h$ of the consumers' ideal points to firm is moderate, when the fraction of variety consumers is small enough or large enough, firms should choose quality commitment. If the unit transportation cost $h$ of the consumers' ideal points to firm is enough small, firms need to adopt the quality commitment. However, the habit formation could not change these tendencies.

In the presence of variety seeking, although the quality levels will be decreased, the average price is decreased more, and thus the consumers surplus is increased and the total profit is decreased. Compared with price commitment, the total profit is decreased, and the consumers can not gain the more surplus form price commitment that may reduce the incentive for variety seeking, but the consumers benefit from quality commitment that will gain more motivation for variety seeking; therefore, the market with quality commitment will lose more from potential variety seeking. Moreover, the habit formation will damage the consumers surplus with quality commitment and does not affect that with price commitment. This fits the empirical observations that more firms choose the price commitment rather than quality commitment.

\section{Conclusion and Future Extensions}

We study competitive pricing and quality strategies in a market with both variety seeking behavior and habit formation. With price commitment, our results show that although variety seeking does not affect the firms' pricing and the average consumers surplus, the quality in period 2 will be improved and in period 1 will be decreased, the total profits of the market will be less than that without variety seeking, we can conclude that the firms need to pay the cost for the potential loss of market share resulting from variety seeking, and the habit formation will benefit firms, and we can explain that consumers need to pay for their inertial. With quality commitment, in contrast with price commitment, although the total profit is also reduced with variety seeking, the average consumers surplus is increased, the same as in Sajeesh and Raju [11], while the habit formation hurts consumers surplus, and firms also gain more from the inertial the same as the case of price commitment.

From the comparison of the price commitment and quality commitment, both the unit transportation cost and the fraction of consumers seeking variety have effect on the firms 
strategies. The enough largeness of $h$ and $\theta$ will prompt firms to choose price commitment; otherwise, they will choose another strategy. Under our model setting, the habitual consumption does not affect these decisions. For preventing variety seeking, our results suggest that the firms will prefer price commitment to quality commitment, under price commitment, the consumers do not gain additive consumers surplus by variety seeking or habitual consumption, and thus it may decrease the incentive for variety seeking.

Although we did not discuss the situation of $\varphi>\theta$, where the number of habitual consumption consumers is more than that of variety seeking consumers, we can easily find the following insights. When $\varphi>\theta$, with price commitment, the firm will supply higher quality levels in period 1 and lower quality levels in period 2, and the total profit of both firms still decreases with $\varphi$. With quality commitment, the firm will charge lower price in period 1 and higher price in period 2 , but both firms will benefit from the habitual consumption.

Finally, some limitations of this paper should be pointed out. First, we assumed that $k<h$, and we only consider that some consumers with variety seeking must conduct repetitive purchase. Then, we just consider these goods that the firms can change the price and quality. In addition, there is a need for more empirical research to understand the moderating role of various conditions affecting firm strategies when consumers seek variety and form habit. As the future work, we will study the oligopoly market, and the asymmetry markets that consumers have different preference or different satiation for each firm.

\section{Appendix}

Proof of Proposition 1. When $\theta=0$ and $\varphi=0$, there are no variety seeking and habitual consumption consumers in the market. Firms decide price $p_{i}$ at period 0 and quality levels $q_{i}$ at period 1 . The utilities that consumers obtain from purchasing product $i, i=1,2$, are $U_{11}=V-p_{1}+\beta q_{1}-h x$ and $U_{21}=V-p_{2}+\beta q_{2}-h(1-x)$. Let $U_{11}=U_{21}$, the indifference point is then $\bar{x}_{0}=\left(p_{2}-p_{1}+\beta\left(q_{1}-q_{2}\right)+h\right) / 2 h$, and, for $x<\bar{x}_{0}$, consumers will purchase from firm 1 . Therefore, each firm's demand is, separately,

$$
\begin{aligned}
& d_{10}^{p}=\frac{p_{2}-p_{1}+\beta\left(q_{1}-q_{2}\right)+h}{2 h} . \\
& d_{20}^{p}=\frac{p_{1}-p_{2}+\beta\left(q_{2}-q_{1}\right)+h}{2 h}
\end{aligned}
$$

Firm 1's and Firm 2's profits are, respectively, given by

$$
\begin{aligned}
& \pi_{10}^{p}=p_{1} \frac{p_{2}-p_{1}+\beta\left(q_{1}-q_{2}\right)+h}{2 h}-\frac{\alpha}{2} q_{1}^{2} \\
& \pi_{20}^{p}=p_{2} \frac{p_{1}-p_{2}+\beta\left(q_{2}-q_{1}\right)+h}{2 h}-\frac{\alpha}{2} q_{2}^{2} .
\end{aligned}
$$

By first-order conditions, given price decision $p_{1}$ and $p_{2}$, $\partial \pi_{10}^{p} / \partial q_{1}=0$ and $\partial \pi_{20}^{p} / \partial q_{2}=0$ at the optimal quality levels. Therefore,

$$
\begin{aligned}
& \frac{\partial \pi_{10}^{p}}{\partial q_{1}}=p_{1} \frac{\beta}{2 h}-\alpha q_{1}=0 \\
& \frac{\partial \pi_{20}^{p}}{\partial q_{2}}=p_{1} \frac{\beta}{2 h}-\alpha q_{2}=0 .
\end{aligned}
$$

We can easily get that $\partial^{2} \pi_{10}^{p} / \partial q_{1}^{2}<0$ and $\partial^{2} \pi_{20}^{p} / \partial q_{2}^{2}<0$ and thus get

$$
\begin{aligned}
& q_{10}^{p}=\frac{p_{1} \beta}{2 h \alpha}, \\
& q_{20}^{p}=\frac{p_{2} \beta}{2 h \alpha} .
\end{aligned}
$$

Similarly, by first-order conditions, $\partial \pi_{10}^{p} / \partial p_{1}=0$ and $\partial \pi_{20}^{p} / \partial p_{2}=0$ at the optimal prices. Combining with (A.4) yields the equilibrium solutions as

$$
\begin{aligned}
\frac{\partial \pi_{10}^{p}}{\partial p_{1}} & =\frac{p_{2}-2 p_{1}+h}{2 h}+\frac{\beta}{2 h} \frac{\beta\left(2 p_{1}-p_{2}\right)}{2 h \alpha}-\frac{\beta^{2} p_{1}}{4 h^{2} \alpha} \\
& =0 \\
\frac{\partial \pi_{20}^{p}}{\partial p_{2}} & =\frac{p_{1}-2 p_{2}+h}{2 h}+\frac{\beta}{2 h} \frac{\beta\left(2 p_{2}-p_{1}\right)}{2 h \alpha}-\frac{\beta^{2} p_{2}}{4 h^{2} \alpha} \\
& =0 .
\end{aligned}
$$

The condition of $2 h \alpha>\beta^{2}$ ensures that $\partial^{2} \pi_{10}^{p} / \partial p_{1}^{2}=-1 / h+$ $\beta^{2} / 4 h^{2} \alpha<0$ and $\partial^{2} \pi_{20}^{p} / \partial p_{2}^{2}=-1 / h+\beta^{2} / 4 h^{2} \alpha<0$. Then we can get the equilibrium price $p_{10}^{p}=p_{20}^{p}=h$ and the optimal quality level $q_{10}^{p}=q_{20}^{p}=\beta / 2 \alpha$. Thus, it is proved.

Proof of Proposition 2. We use backward approach for proving. For $\theta>0$, we can write firm 1 and firm 2 profits in period 2 as follows:

$$
\begin{aligned}
\pi_{12}^{p} & =p_{1}\left[(1+\theta-\varphi) \frac{\beta\left(q_{12}-q_{22}\right)}{2 h}+\frac{p_{2}-p_{1}+h}{2 h}\right. \\
& \left.+(\varphi-\theta) \frac{\beta\left(q_{11}-q_{21}\right)}{2 h}\right]-\frac{\alpha}{2} q_{12}^{2} \\
\pi_{22}^{p} & =p_{2}\left[(1+\theta-\varphi) \frac{\beta\left(q_{22}-q_{12}\right)}{2 h}+\frac{p_{1}-p_{2}+h}{2 h}\right. \\
& \left.+(\varphi-\theta) \frac{\beta\left(q_{21}-q_{11}\right)}{2 h}\right]-\frac{\alpha}{2} q_{22}^{2} .
\end{aligned}
$$

Each firm chooses their quality levels $\left(q_{12}\right.$ and $\left.q_{22}\right)$ to maximize profits assuming the quality levels in period 1 
$\left(q_{11}\right.$ and $\left.q_{21}\right)$ and prices $\left(p_{1}\right.$ and $\left.p_{2}\right)$ are given. Therefore, $\partial \pi_{12}^{p} / \partial q_{12}=0$ and $\partial \pi_{22}^{p} / \partial q_{22}$. Solving, we get

$$
\begin{aligned}
& \frac{\partial \pi_{12}^{p}}{\partial q_{12}}=\frac{p_{1}(1+\theta-\varphi) \beta}{2 h}-\alpha q_{12}=0 \\
& \frac{\partial \pi_{22}^{p}}{\partial q_{22}}=\frac{p_{2}(1+\theta-\varphi) \beta}{2 h}-\alpha q_{22}=0 .
\end{aligned}
$$

We can get $\partial^{2} \pi_{12}^{p} / \partial q_{12}^{2}<0$ and $\partial^{2} \pi_{22}^{p} / \partial q_{22}^{2}<0$. Solving the expressions for $q_{12}$ and $q_{22}$ simultaneously, we get

$$
\begin{aligned}
& q_{12}^{p}=(1+\theta-\varphi) \beta \frac{p_{1}}{2 h \alpha} \\
& q_{22}^{p}=(1+\theta-\varphi) \beta \frac{p_{2}}{2 h \alpha} .
\end{aligned}
$$

Next, each firm decides $q_{11}$ and $q_{21}$ to maximize their total profits in two periods (as indicated in (12)), given prices $p_{1}$ and $p_{2}$ are determined separately in period 0 . Then

$$
\begin{aligned}
\pi_{1}^{p} & =p_{1}\left[(1+\theta-\varphi)^{2} \frac{\beta^{2}\left(p_{1}-p_{2}\right)}{4 h^{2} \alpha}+\frac{p_{2}-p_{1}+h}{h}\right. \\
& \left.+(1+\varphi-\theta) \frac{\beta\left(q_{11}-q_{21}\right)}{2 h}\right]-\frac{\alpha}{2} q_{11}^{2} \\
& -\frac{\alpha}{2}\left[(1+\theta-\varphi) \beta \frac{p_{1}}{2 h \alpha}\right]^{2} . \\
\pi_{2}^{p} & =p_{2}\left[(1+\theta-\varphi)^{2} \frac{\beta^{2}\left(p_{2}-p_{1}\right)}{4 h^{2} \alpha}+\frac{p_{1}-p_{2}+h}{h}\right. \\
& \left.+(1+\varphi-\theta) \frac{\beta\left(q_{21}-q_{11}\right)}{2 h}\right]-\frac{\alpha}{2} q_{21}^{2} \\
& -\frac{\alpha}{2}\left[(1+\theta-\varphi) \beta \frac{p_{2}}{2 h \alpha}\right]^{2}
\end{aligned}
$$

As $\partial^{2} \pi_{1}^{p} / \partial q_{11}^{2}<0$ and $\partial^{2} \pi_{2}^{p} / \partial q_{21}^{2}<0$, solving, $\partial \pi_{1}^{p} / \partial q_{11}=0$ and $\partial \pi_{2}^{p} / \partial q_{21}=0$. Similarly, we get

$$
\begin{aligned}
& q_{11}^{p}=(1+\varphi-\theta) \beta \frac{p_{1}}{2 h \alpha} \\
& q_{21}^{p}=(1+\varphi-\theta) \beta \frac{p_{2}}{2 h \alpha} .
\end{aligned}
$$

Lastly, firms decide $p_{1}$ and $p_{2}$ at period 0 to maximize their total profits. Then we can get

$$
\begin{aligned}
\frac{\partial \pi_{1}^{p}}{\partial p_{1}}= & {\left[1+(\theta-\varphi)^{2}\right] \frac{\beta^{2}\left(2 p_{1}-p_{2}\right)}{2 h^{2} \alpha} } \\
& +\frac{p_{2}-2 p_{1}+h}{h}-\left[1+(\theta-\varphi)^{2}\right] \frac{\beta^{2} p_{1}}{2 h^{2} \alpha} \\
\frac{\partial \pi_{2}^{p}}{\partial p_{2}}= & {\left[1+(\theta-\varphi)^{2}\right] \frac{\beta^{2}\left(2 p_{2}-p_{1}\right)}{2 h^{2} \alpha} } \\
& +\frac{p_{1}-2 p_{2}+h}{h}-\left[1+(\theta-\varphi)^{2}\right] \frac{\beta^{2} p_{2}}{2 h^{2} \alpha} .
\end{aligned}
$$

The condition of $2 h \alpha>\beta^{2}$ ensures that $\partial^{2} \pi_{1}^{p} / \partial p_{1}^{2}=$ $\partial^{2} \pi_{2}^{p} / \partial p_{2}^{2}=-2 / h+\left[1+(\theta-\varphi)^{2}\right]\left(\beta^{2} / 2 h^{2} \alpha\right)<0$. By firstorder conditions the optimal prices are $p_{1}^{p}=p_{2}^{p}=h$. Substituting $p_{1}^{p}$ and $p_{2}^{p}$ into (A.8) and (A.10), we can now get the equilibrium solutions of the quality levels; that is, $q_{12}^{p}=q_{22}^{p}=$ $((1+\theta-\varphi) / 2 \alpha) \beta$ and $q_{11}^{p}=q_{21}^{p}=((1+\varphi-\theta) / 2 \alpha) \beta$. Then, we can get $\left(q_{i 1}^{p}+q_{i 2}^{p}\right) / 2=q_{i 0}^{p}, \forall i=1,2$. Thus, it is proved.

Proof of Proposition 3. Notice the average quality level over periods 1 and 2 can be calculated by $\left(q_{i 1}^{p}+q_{\mathrm{i} 2}^{p}\right) / 2=\beta / 2 \alpha=$ $q_{i 0}^{p}, \forall i=1,2$. Therefore, the average quality level obtained by the consumers over the two periods is the same as in a market without variety seeking consumers and habitual consumption consumers. Further notice that $p_{i j}^{p}=p_{i 0}^{p}=h$, meaning prices are the same no matter if there are variety seeking consumers and habitual consumption consumers or not. Therefore, the average consumers surplus is the same.

Substituting the equilibrium solutions into (12) yields the total profit for each firm:

$$
\begin{aligned}
\pi_{i}^{p}= & \pi_{i 1}^{p}+\pi_{i 2}^{p} \\
= & \frac{h}{2}-\frac{\alpha}{2}\left(\frac{(1+\varphi-\theta) \beta}{2 \alpha}\right)^{2}+\frac{h}{2} \\
& -\frac{\alpha}{2}\left(\frac{(1+\theta-\varphi) \beta}{2 \alpha}\right)^{2} \\
= & h-\frac{\beta^{2}}{4 \alpha}\left[1+(\theta-\varphi)^{2}\right]
\end{aligned}
$$

when $\varphi=0$, where there is no habitual consumption, we can get $\pi_{i}^{p}=h-\left(\beta^{2} / 4 \alpha\right)\left(1+\theta^{2}\right)<h-\beta^{2} / 4 \alpha=2 \pi_{i 0}^{p}$, the presence of variety seeking reduces the firms' profit, when $0<\varphi<\theta$, where there is habitual consumption, we can get $\pi_{i}^{p}=h-$ $\left(\beta^{2} / 4 \alpha\right)\left(1+\theta^{2}\right)<h-\left(\beta^{2} / 4 \alpha\right)\left[1+(\theta-\varphi)^{2}\right]$, and the habitual consumption reduces the loss results of variety seeking. Thus, proved.

Proof of Proposition 4. When $\theta=0$ and $\varphi=0$, there are no variety seeking and habitual consumption consumers in the market. Firms decide quality levels $q_{i}$ at period 0 and price $p_{i}$ at period 1 . Similarly, each firm's demand is, separately,

$$
\begin{aligned}
& d_{10}^{q}=\frac{p_{2}-p_{1}+\beta\left(q_{1}-q_{2}\right)+h}{2 h} \\
& d_{20}^{q}=\frac{p_{1}-p_{2}+\beta\left(q_{2}-q_{1}\right)+h}{2 h} .
\end{aligned}
$$

Firm 1's and Firm 2's profits are, respectively, given by

$$
\begin{aligned}
& \pi_{10}^{q}=p_{1} \frac{p_{2}-p_{1}+\beta\left(q_{1}-q_{2}\right)+h}{2 h}-\frac{\alpha}{2} q_{1}^{2} \\
& \pi_{20}^{q}=p_{2} \frac{p_{1}-p_{2}+\beta\left(q_{2}-q_{1}\right)+h}{2 h}-\frac{\alpha}{2} q_{2}^{2} .
\end{aligned}
$$


By first-order conditions, given quality levels $q_{1}$ and $q_{2}$, $\partial \pi_{10}^{q} / \partial p_{1}=0$ and $\partial \pi_{20}^{q} / \partial p_{2}=0$ at the optimal price decision. Therefore,

$$
\begin{aligned}
& \frac{\partial \pi_{10}^{q}}{\partial p_{1}}=\frac{p_{2}-2 p_{1}+\beta\left(q_{1}-q_{2}\right)+h}{2 h}=0 . \\
& \frac{\partial \pi_{20}^{q}}{\partial p_{2}}=\frac{p_{1}-2 p_{2}+\beta\left(q_{2}-q_{1}\right)+h}{2 h}=0
\end{aligned}
$$

We can easily get that $\partial^{2} \pi_{10}^{q} / \partial p_{1}^{2}<0$ and $\partial^{2} \pi_{20}^{q} / \partial p_{2}^{2}<0$, and then

$$
\begin{aligned}
& p_{10}=\frac{3 h+\beta\left(q_{1}-q_{2}\right)}{3} \\
& p_{20}=\frac{3 h+\beta\left(q_{2}-q_{1}\right)}{3} .
\end{aligned}
$$

Submitting (A.16) to (A.17), one gets

$$
\begin{aligned}
& \pi_{10}^{q}=\frac{\left[3 h+\beta\left(q_{1}-q_{2}\right)\right]^{2}}{18 h}-\frac{\alpha}{2} q_{1}^{2} \\
& \pi_{20}^{q}=\frac{\left[3 h+\beta\left(q_{2}-q_{1}\right)\right]^{2}}{18 h}-\frac{\alpha}{2} q_{2}^{2}
\end{aligned}
$$

Similarly, by first-order conditions, $\partial \pi_{10}^{q} / \partial q_{1}=0$ and $\partial \pi_{20}^{q} / \partial q_{2}=0$ at the optimal quality level:

$$
\begin{aligned}
& \frac{\partial \pi_{10}^{q}}{\partial q_{1}}=\beta \frac{3 h+\beta\left(q_{1}-q_{2}\right)}{9 h}-\alpha q_{1} \\
& \frac{\partial \pi_{10}^{q}}{\partial q_{2}}=\beta \frac{3 h+\beta\left(q_{2}-q_{1}\right)}{9 h}-\alpha q_{2} .
\end{aligned}
$$

The condition of $\beta^{2}<2 h \alpha$ ensures $\partial^{2} \pi_{10}^{q} / \partial q_{1}^{2}=\beta^{2} / 9 h-$ $\alpha<0$ and $\partial^{2} \pi_{20}^{q} / \partial q_{2}^{2}=\beta^{2} / 9 h-\alpha<0$. Therefore, we can obtain the equilibrium quality level $q_{10}^{q}=q_{20}^{q}=\beta / 3 \alpha$ and then get the optimal price $p_{10}^{q}=p_{20}^{q}=h$. Thus, it is proved.

Proof of Proposition 5. Firm 1 and firm 2 profits in period 2 are, respectively, given by

$$
\begin{aligned}
& \pi_{12}^{q}=p_{12} d_{12}^{q}-\frac{\alpha}{2} q_{1}^{2} \\
& \pi_{22}^{q}=p_{22} d_{22}^{q}-\frac{\alpha}{2} q_{2}^{2} .
\end{aligned}
$$

Substituting (18) and (19) to the profit function, we can get

$$
\begin{aligned}
\pi_{12}^{q} & =p_{12}\left[(1+\theta) \frac{p_{22}-p_{12}}{2 h}+\frac{\beta\left(q_{1}-q_{2}\right)+h}{2 h}\right. \\
& \left.-\theta \frac{p_{21}-p_{11}}{2 h}\right]-\frac{\alpha}{2} q_{1}^{2} \\
\pi_{22}^{q} & =p_{22}\left[(1+\theta) \frac{p_{12}-p_{22}}{2 h}+\frac{\beta\left(q_{2}-q_{1}\right)+h}{2 h}\right. \\
& \left.-\theta \frac{p_{11}-p_{21}}{2 h}\right]-\frac{\alpha}{2} q_{2}^{2} .
\end{aligned}
$$

In period 2 , firms choose $p_{12}$ and $p_{22}$ to maximize profits assuming quality and price are given in period 1 . First-order derivative yields

$$
\begin{aligned}
\frac{\partial \pi_{12}^{q}}{\partial p_{12}}= & (1+\theta-\varphi) \frac{p_{22}-2 p_{12}}{2 h}+\frac{\beta\left(q_{1}-q_{2}\right)+h}{2 h} \\
& -(\theta-\varphi) \frac{p_{21}-p_{11}}{2 h} \\
\frac{\partial \pi_{22}^{q}}{\partial p_{22}}= & (1+\theta-\varphi) \frac{p_{12}-2 p_{22}}{2 h}+\frac{\beta\left(q_{2}-q_{1}\right)+h}{2 h} \\
& -(\theta-\varphi) \frac{p_{11}-p_{21}}{2 h} .
\end{aligned}
$$

We can get $\partial^{2} \pi_{12}^{q} / \partial p_{12}^{2}<0$ and $\partial^{2} \pi_{22}^{q} / \partial p_{22}^{2}<0$, by jointly solving the first-order conditions, and then

$$
\begin{aligned}
& p_{12}=\frac{3 h+\beta\left(q_{1}-q_{2}\right)-(\theta-\varphi)\left(p_{21}-p_{11}\right)}{3(1+\theta-\varphi)} \\
& p_{22}=\frac{3 h+\beta\left(q_{2}-q_{1}\right)-(\theta-\varphi)\left(p_{11}-p_{21}\right)}{3(1+\theta-\varphi)} .
\end{aligned}
$$

Substituting (13), (18), and (19) to the total profit function (20), we can get the profit of each firm:

$$
\begin{aligned}
\pi_{1}^{q}= & p_{11} \frac{p_{21}-p_{11}+\beta\left(q_{1}-q_{2}\right)+h}{2 h} \\
& +\frac{\left[3 h+\beta\left(q_{1}-q_{2}\right)-(\theta-\varphi)\left(p_{21}-p_{11}\right)\right]^{2}}{18 h(1+\theta-\varphi)} \\
& -\frac{\alpha}{2} q_{1}^{2}-\frac{\alpha}{2} q_{1}^{2} \\
\pi_{2}^{q}= & p_{21} \frac{p_{11}-p_{21}+\beta\left(q_{2}-q_{1}\right)+h}{2 h} \\
& +\frac{\left[3 h+\beta\left(q_{2}-q_{1}\right)-(\theta-\varphi)\left(p_{11}-p_{21}\right)\right]^{2}}{18 h(1+\theta-\varphi)} \\
& -\frac{\alpha}{2} q_{2}^{2}-\frac{\alpha}{2} q_{2}^{2} .
\end{aligned}
$$

In period 1 , firms choose $p_{11}$ and $p_{21}$ to maximize profits. Similarly, we get

$$
\begin{aligned}
& \frac{\partial \pi_{1}^{q}}{\partial p_{11}}=\frac{p_{21}-2 p_{11}+\beta\left(q_{1}-q_{2}\right)+h}{2 h} \\
&+ \frac{\left[3 h+\beta\left(q_{1}-q_{2}\right)-(\theta-\varphi)\left(p_{21}-p_{11}\right)\right](\theta-\varphi)}{9 h(1+\theta-\varphi)} \\
& \frac{\partial \pi_{2}^{q}}{\partial p_{21}}=\frac{p_{11}-2 p_{21}+\beta\left(q_{2}-q_{1}\right)+h}{2 h} \\
&+\frac{\left[3 h+\beta\left(q_{2}-q_{1}\right)-(\theta-\varphi)\left(p_{11}-p_{21}\right)\right](\theta-\varphi)}{9 h(1+\theta-\varphi)} .
\end{aligned}
$$


As $0<\varphi<\theta<1$, then we get $\partial^{2} \pi_{1}^{q} / \partial p_{11}^{2}=-1 / h+(\theta-$ $\varphi)^{2} / 9 h(1+\theta-\varphi)<0$ and $\partial^{2} \pi_{2}^{q} / \partial p_{21}^{2}=-1 / h+(\theta-\varphi)^{2} / 9 h(1+$ $\theta-\varphi)<0$, and thus we can get the price

$$
\begin{aligned}
p_{11}= & \frac{3+5(\theta-\varphi)}{3(1+\theta-\varphi)} h \\
& +\frac{[9+11(\theta-\varphi)] \beta}{27+27(\theta-\varphi)-4(\theta-\varphi)^{2}}\left(q_{1}-q_{2}\right)
\end{aligned}
$$

$$
\begin{aligned}
p_{21}= & \frac{3+5(\theta-\varphi)}{3(1+\theta-\varphi)} h \\
& +\frac{[9+11(\theta-\varphi)] \beta}{27+27(\theta-\varphi)-4(\theta-\varphi)^{2}}\left(q_{2}-q_{1}\right) .
\end{aligned}
$$

Thus, firms choose $q_{1}$ and $q_{2}$ to maximize profits. We find $q_{1}$ and $q_{2}$ to be as follows:

$$
\begin{aligned}
& \frac{\partial \pi_{1}^{q}}{\partial q_{1}}=\frac{[9+11(\theta-\varphi)] \beta}{27+27(\theta-\varphi)-4(\theta-\varphi)^{2}}\left[\frac{\beta\left(q_{1}-q_{2}\right)+h}{2 h}-\frac{[9+11(\theta-\varphi)] \beta\left(q_{1}-q_{2}\right)}{h\left(27+27(\theta-\varphi)-4(\theta-\varphi)^{2}\right)}\right]+\left[\frac{3+5(\theta-\varphi)}{3(1+\theta-\varphi)}\right. \\
& \left.+\frac{[9+11(\theta-\varphi)] \beta\left(q_{1}-q_{2}\right)}{27+27(\theta-\varphi)-4(\theta-\varphi)^{2}}\right]\left[\frac{\beta}{2 h}-\frac{[9+11(\theta-\varphi)] \beta}{h\left(27+27(\theta-\varphi)-4(\theta-\varphi)^{2}\right)}\right] \\
& +\frac{\left[3 h+\beta\left(q_{1}-q_{2}\right)+(\theta-\varphi)\left([18+22(\theta-\varphi)] \beta\left(q_{1}-q_{2}\right) /\left(27+27(\theta-\varphi)-4(\theta-\varphi)^{2}\right)\right)\right]}{9 h(1+\theta-\varphi)}[\beta \\
& \left.+\beta \frac{[18+22(\theta-\varphi)](\theta-\varphi)}{27+27(\theta-\varphi)-4(\theta-\varphi)^{2}}\right]-2 \alpha q_{1} \\
& \frac{\partial \pi_{2}^{q}}{\partial q_{2}}=\frac{[9+11(\theta-\varphi)] \beta}{27+27(\theta-\varphi)-4(\theta-\varphi)^{2}}\left[\frac{\beta\left(q_{2}-q_{1}\right)+h}{2 h}-\frac{[9+11(\theta-\varphi)] \beta\left(q_{2}-q_{1}\right)}{h\left(27+27(\theta-\varphi)-4(\theta-\varphi)^{2}\right)}\right]+\left[\frac{3+5(\theta-\varphi)}{3(1+\theta-\varphi)} h\right. \\
& \left.+\frac{[9+11(\theta-\varphi)] \beta\left(q_{2}-q_{1}\right)}{27+27(\theta-\varphi)-4(\theta-\varphi)^{2}}\right]\left[\frac{\beta}{2 h}-\frac{[9+11(\theta-\varphi)] \beta}{h\left(27+27(\theta-\varphi)-4(\theta-\varphi)^{2}\right)}\right] \\
& \left.+\beta \frac{[18+22(\theta-\varphi)](\theta-\varphi)}{27+27(\theta-\varphi)-4(\theta-\varphi)^{2}}\right]-2 \alpha q_{2} . \\
& \quad+\frac{\left[3 h+\beta\left(q_{2}-q_{1}\right)+(\theta-\varphi)\left([18+22(\theta-\varphi)] \beta\left(q_{2}-q_{1}\right) /\left(27+27(\theta-\varphi)-4(\theta-\varphi)^{2}\right)\right)\right]}{9 h(1+\theta-\varphi)}[\beta
\end{aligned}
$$

Then we can get the second-order derivative

$$
\begin{aligned}
& \frac{\partial^{2} \pi_{1}^{q}}{\partial q_{1}^{2}}=\frac{2[9+11(\theta-\varphi)] \beta}{27+27(\theta-\varphi)-4(\theta-\varphi)^{2}}\left[\frac{\beta}{2 h}\right. \\
& \left.-\frac{[9+11(\theta-\varphi)] \beta}{h\left(27+27(\theta-\varphi)-4(\theta-\varphi)^{2}\right)}\right] \\
& +\frac{1}{9 h(1+\theta-\varphi)}[\beta \\
& \left.+\beta \frac{[18+22(\theta-\varphi)](\theta-\varphi)}{27+27(\theta-\varphi)-4(\theta-\varphi)^{2}}\right]^{2}-2 \alpha
\end{aligned}
$$

$$
\begin{gathered}
\frac{\partial^{2} \pi_{2}^{q}}{\partial q_{2}^{2}}=\frac{2[9+11(\theta-\varphi)] \beta}{27+27(\theta-\varphi)-4(\theta-\varphi)^{2}}\left[\frac{\beta}{2 h}\right. \\
\left.-\frac{[9+11(\theta-\varphi)] \beta}{h\left(27+27(\theta-\varphi)-4(\theta-\varphi)^{2}\right)}\right] \\
+\frac{1}{9 h(1+\theta-\varphi)}[\beta \\
\left.+\beta \frac{[18+22(\theta-\varphi)](\theta-\varphi)}{27+27(\theta-\varphi)-4(\theta-\varphi)^{2}}\right]^{2}-2 \alpha .
\end{gathered}
$$


As $0<\varphi<\theta<0$, we get $(2[9+11(\theta-\varphi)] \beta /(27+27(\theta-\varphi)-$ $\left.\left.4(\theta-\varphi)^{2}\right)\right)\left[\beta / 2 h-[9+11(\theta-\varphi)] \beta / h\left(27+27(\theta-\varphi)-4(\theta-\varphi)^{2}\right)\right]<$ $\beta^{2} / 9 h$, where $\theta=\varphi$ and $(1 / 9 h(1+\theta-\varphi))[\beta+\beta([18+22(\theta-$ $\left.\left.\varphi)](\theta-\varphi) /\left(27+27(\theta-\varphi)-4(\theta-\varphi)^{2}\right)\right)\right]^{2}<9 \beta^{2} / 50 h$, where $\theta=$ 1 and $\varphi=0$. Then we can get the condition of $2 h \alpha>(9 / 50+$ $1 / 9) \beta^{2}$ ensuring $\partial^{2} \pi_{1}^{q} / \partial q_{1}^{2}<0$ and $\partial^{2} \pi_{2}^{q} / \partial q_{2}^{2}<0$. Thus, we get the equilibrium quality level $q_{1}^{q}=q_{2}^{q}=\beta[54+105(\theta-\varphi)$ $\left.+41(\theta-\varphi)^{2}-10(\theta-\varphi)^{3}\right] / 6 \alpha(1+\theta-\varphi)\left(27+27(\theta-\varphi)-4(\theta-\varphi)^{2}\right)$ and the optimal price in both periods $p_{11}^{q}=p_{21}^{q}=((3+5)$ $\varphi)) / 3(1+\theta-\varphi)) h$ and $p_{12}^{q}=p_{22}^{q}=h /(1+\theta-\varphi)$.

Notice, for $0<v=\theta-\varphi<1, p_{i 1}^{q}=h+2 h v / 3(1+v)>p_{i 2}^{q}=$ $h-3 h v / 3(1+v)$ and $p_{i 1}^{q}-p_{i 2}^{q}=5 h v / 3(1+\nu)$, thus the price gap increases with $\nu$, and, therefore, thus the price gap increases with $\theta$ and decreases with $\varphi$. In addition, $\partial q_{i}^{q} / \partial v=-\beta(81+$ $\left.270 v+363 v^{2}+240 v^{3}+66 v^{4}\right) / 6 \alpha\left(27+54 v+23 v^{2}-4 v^{3}\right)^{2}<0$, and thus the quality decreases with $\theta$ and increases with $\varphi$.

Proof of Proposition 6. Let $0<\nu=\theta-\varphi<1$, and we get that

$$
\begin{aligned}
\frac{p_{12}^{q}+p_{11}^{q}}{2} & =\frac{p_{22}^{q}+p_{21}^{q}}{2}=h-\frac{h \nu}{6(1+\nu)} \\
q_{1}^{q} & =q_{2}^{q}=\frac{\beta\left(54+105 v+41 \nu^{2}-10 \nu^{3}\right)}{6 \alpha(1+\nu)\left(27+27 v-4 v^{2}\right)}
\end{aligned}
$$

and then we can easily get that $\left(U_{11}+U_{12}\right) / 2-U_{10}=h v / 6(1+$ $\nu)+\beta^{2}\left(54+105 \nu+41 \nu^{2}-10 \nu^{3}\right) / 6 \alpha(1+\nu)\left(27+27 \nu-4 \nu^{2}\right)-\beta^{2} / 3 \alpha$. Let $f(\nu)=h v / 6(1+v)$ and $g(v)=-\beta^{2}\left(54+105 v+41 v^{2}-\right.$ $\left.10 v^{3}\right) / 6 \alpha(1+v)\left(27+27 v-4 v^{2}\right)$, and we get $\partial f(v) / \partial v>0$, $\partial^{2} f(\nu) / \partial \nu^{2}<0, \partial g(\nu) / \partial \nu>0$, and $\partial^{2} g(\nu) / \partial \nu^{2}<0$, as the condition $2 h \alpha>\beta^{2}$, we can get $f(1)-g(1)-\beta^{2} / 3 \alpha=h / 12-$ $\beta^{2} / 60 \alpha>0$, and, therefore, we get $\left(U_{11}+U_{12}\right) / 2-U_{10}>0$. Thus, it is proved.

Under quality commitment, substituting the equilibrium solutions into the profit function (20), the total profit of the market with quality commitment is

$$
\begin{aligned}
\pi_{1}^{q}= & \pi_{2}^{q} \\
= & \frac{h(6+5 v)}{6+6 \nu} \\
& -\frac{\beta^{2}}{36 \alpha}\left(\frac{54+105 v+41 v^{2}-10 \nu^{3}}{27+54 \nu+23 v^{2}-4 \nu^{3}}\right)^{2} .
\end{aligned}
$$

Then we can get

$$
\frac{\partial \pi_{1}^{q}}{\partial \nu}=\frac{\partial \pi_{2}^{q}}{\partial \nu}=\frac{-h}{6(1+v)^{2}}+\frac{\beta^{2}\left(54+105 v+41 v^{2}-10 \nu^{3}\right)\left(81+270 \nu+363 v^{2}+240 \nu^{3}+66 \nu^{4}\right)}{18 \alpha\left(27+54 \nu+23 v^{2}-4 \nu^{3}\right)^{3}}
$$

Note

$$
\begin{aligned}
& H(\nu)=\frac{-h}{6(1+v)^{2}}<0 \\
& G(\nu)=-\frac{\beta^{2}\left(54+105 v+41 v^{2}-10 v^{3}\right)\left(81+270 v+363 v^{2}+240 v^{3}+66 v^{4}\right)}{18 \alpha\left(27+54 v+23 v^{2}-4 v^{3}\right)^{3}}<0 .
\end{aligned}
$$

Easily, we can get $H(\nu)^{\prime}>0$ and $G(\nu)^{\prime}>0$.

Then we get that

$$
\begin{aligned}
& H(0)=-\frac{h}{6}<G(0)=-\frac{\beta^{2}}{81 \alpha}<0, \\
& H(1)=-\frac{h}{24}<G(1)=-\frac{323 \beta^{2}}{30000 \alpha}<0 .
\end{aligned}
$$

For $v \in(0,1)$, thus $H(\nu)^{\prime}-G(v)^{\prime}<0$ and then $f(\nu)^{\prime}=$ $H(\nu)^{\prime}-G(\nu)^{\prime}<0$, and the total profit decreased with variety seeking and increased with habitation consumption. Thus, it is proved.

Proof of Theorem 7. As $0<\varphi<\theta<1$, assuming $\varphi=0$, substituting the equilibrium solutions into the profit function
(20), the total profit of the market with quality commitment is

$$
\begin{aligned}
\pi_{1}^{q}= & \pi_{2}^{q} \\
= & \frac{h(6+5 \theta)}{6+6 \theta} \\
& -\frac{\beta^{2}}{36 \alpha}\left(\frac{54+105 \theta+41 \theta^{2}-10 \theta^{3}}{27+54 \theta+23 \theta^{2}-4 \theta^{3}}\right)^{2} .
\end{aligned}
$$

Similarly, we can get the total profit of the market with price commitment is

$$
\pi_{1}^{p}=\pi_{2}^{p}=h-\frac{\beta^{2}}{4 \alpha}\left(1+\theta^{2}\right) .
$$


As the condition of $h-\beta^{2} / 2 \alpha>0$ ensures that the profit with each strategy is always positive, then we can get

$$
\begin{aligned}
\pi_{1}^{q} & -\pi_{1}^{p} \\
& =\frac{h}{6+6 \theta}
\end{aligned}
$$

$$
\begin{aligned}
& +\frac{\beta^{2}}{36 \alpha}\left[9 \theta^{2}-\left(\frac{54+105 \theta+41 \theta^{2}-10 \theta^{3}}{27+54 \theta+23 \theta^{2}-4 \theta^{3}}\right)^{2}\right] \\
& -\frac{h}{6}+\frac{\beta^{2}}{4 \alpha} .
\end{aligned}
$$

Let $F(\theta)=\pi_{1}^{q}-\pi_{1}^{p}$ and $f(\theta)=\partial F(\theta) / \partial \theta$, and then we can get

$$
f(\theta)=\frac{-h}{6(1+\theta)^{2}}+\frac{\beta^{2}}{18 \alpha}\left[9 \theta+\frac{\left(54+105 \theta+41 \theta^{2}-10 \theta^{3}\right)\left(81+270 \theta+363 \theta^{2}+240 \theta^{3}+66 \theta^{4}\right)}{\left(27+54 \theta+23 \theta^{2}-4 \theta^{3}\right)^{3}}\right] .
$$

Note $H(\theta)=-h / 6(1+\theta)^{2}$ and $h(\theta)=9 \theta+(54+105 \theta+$ $\left.41 \theta^{2}-10 \theta^{3}\right)\left(81+270 \theta+363 \theta^{2}+240 \theta^{3}+66 \theta^{4}\right) /(27+54 \theta+$ $\left.23 \theta^{2}-4 \theta^{3}\right)^{3}$. For $0<\theta<1$ we can get $H(\theta)^{\prime}>0$ and $h(\theta)^{\prime}>0$, and then $f(\theta)^{\prime}>0$. As the condition $h>\beta^{2} / 2 \alpha$, we can get $f(0)=-(1 / 6)\left(h-2 \beta^{2} / 27 \alpha\right)<0$ and $f(1)=$ $-h / 24+15323 \beta^{2} / 30000 \alpha$. Then, $F(0)=5 \beta^{2} / 36 \alpha>0$ and $F(1)=-h / 12+1439 \beta^{2} / 3600 \alpha$.

Then we can get that if $F(1)=-h / 12+1439 \beta^{2} / 3600 \alpha<0$, then $h>1439 \beta^{2} / 300 \alpha$ and if $F(1)=-h / 12+1439 \beta^{2} / 3600 \alpha>$ 0 , then $h<1439 \beta^{2} / 300 \alpha$.

(I) If $f(1)=-h / 24+15323 \beta^{2} / 30000 \alpha<0$, then $h>$ $15323 \beta^{2} / 1250 \alpha$, when $0<\theta<1$, we can get $f(\theta)<$ 0 , and then $F(\theta)$ decreased with $\theta$, and $F(0)>0$, $F(1)=-h / 12+1439 \beta^{2} / 3600 \alpha<0$, then we can get $\theta^{*} \in(0,1)$, when $\theta \in\left(0, \theta^{*}\right), F(\theta)>0$, then the total profit with quality commitment is better, when $\theta \in\left(\theta^{*}, 1\right), F(\theta)<0$, and then the total profit with price commitment is better.

(II) If $f(1)=-h / 24+15323 \beta^{2} / 30000 \alpha>0$, then $h<$ $15323 \beta^{2} / 1250 \alpha$, and when $0<\theta<1$, we can get then that $F(\theta)$ decreased first and then increased with $\theta$.

(i) If $1439 \beta^{2} / 300 \alpha<h<15323 \beta^{2} / 1250 \alpha$, we can get $F(0)>0$ and $F(1)=-h / 12+$ $1439 \beta^{2} / 3600 \alpha<0$, and then we can get $\widehat{\theta}^{*} \epsilon$ $(0,1)$, and when $\theta \in\left(0, \widehat{\theta}^{*}\right)$ and $F(\theta)>0$, then the total profit with quality commitment is better, and when $\theta \in\left(\widehat{\theta}^{*}, 1\right)$ and $F(\theta)<0$, then the total profit with price commitment is better.

(ii) If $h<1439 \beta^{2} / 300 \alpha$, we can get $F(0)>0$ and $F(1)=-h / 12+1439 \beta^{2} / 3600 \alpha>0$, and as $\partial F(\theta) / \partial h=-\theta / 6(1+\theta)<0$, then we can get that $F(\theta)$ decreased with $h$. As $F(\theta)$ decreased first and then increased with $\theta$, we get $\theta_{0}^{*} \in$ $(0,1)$ and $F\left(\theta_{0}^{*}\right)<F(\theta)$, and existing $h^{*}$ makes $F\left(\theta_{0}^{*}, h^{*}\right)=0$, when $h^{*}<h<1439 \beta^{2} / 300 \alpha$ and $F\left(\theta_{0}^{*}, h\right)<0$, thus existing $0<\theta_{1}^{*}<\theta_{0}^{*}<\theta_{2}^{*}<$ 1 , when $\theta \in\left(0, \theta_{1}^{*}\right)$, then the total profit with quality commitment will always be better, when $\theta \in\left(\theta_{1}^{*}, \theta_{2}^{*}\right)$, then the total profit with price commitment will always be better, when $\theta \in$ $\left(\theta_{2}^{*}, 1\right)$, the total profit with quality commitment will always be better, and when $h<h^{*}$ and $F\left(\theta_{0}^{*}, h^{*}\right)>0$, then the total profit with quality commitment is better. Thus, it is proved.

\section{Competing Interests}

The authors declare that there is no conflict of interests regarding the publication of this paper.

\section{References}

[1] B. E. Kahn, "Consumer variety-seeking among goods and services: an integrative review," Journal of Retailing and Consumer Services, vol. 2, no. 3, pp. 139-148, 1995.

[2] P. M. Groves and R. F. Thompson, "Habituation: a dual-process theory," Psychological Review, vol. 77, no. 5, pp. 419-450, 1970.

[3] R. L. Solomon, "The opponent-process theory of acquired motivation: the costs of pleasure and the benefits of pain," American Psychologist, vol. 35, no. 8, pp. 691-712, 1980.

[4] L. McAlister and E. Pessemier, "Variety seeking behavior: an interdisciplinary review," Journal of Consumer Research, vol. 9, no. 3, pp. 311-322, 1982.

[5] A. P. Jeuland, "Brand preferences over time: a partially deterministic operationalization of the notion of variety seeking," in Research Frontiers in Marketing: Dialogues and Directions, S. Jain, Ed., vol. 43, pp. 33-37, AMA 1978 Educators Proc., American Marketing Association, Chicago, Ill, USA, 1978.

[6] H. Che, K. Sudhir, and P. B. Seetharaman, "Bounded rationality in pricing under state-dependent demand: do firms look ahead, and if so, how far?" Journal of Marketing Research, vol. 44, no. 3, pp. 434-449, 2007.

[7] R. A. Pollak, "Habit formation and dynamic demand functions," Journal of Political Economy, vol. 78, no. 4, pp. 745-763, 1970.

[8] D. E. Bell, "A utility function for time streams having interperiod dependencies," Journal of Operation Research, vol. 25, no. 3, pp. 448-458, 1977.

[9] G. S. Becker, "Habits, addictions, and traditions," Kyklos, vol. 45, no. 3, pp. 327-345, 1992.

[10] D. Read, G. Loewenstein, and M. Rabin, “Choice bracketing," Journal of Risk and Uncertainty, vol. 19, no. 1-3, pp. 171-197, 1999. 
[11] S. Sajeesh and J. S. Raju, "Positioning and pricing in a variety seeking market," Management Science, vol. 56, no. 6, pp. 949961, 2010 .

[12] Y. Wei, L. Y. Xiong, and Y. L. Wang, "Competition in a variety seeking market with brandname awareness," Working Paper, Jinan University, 2016.

[13] M. Baucells and R. K. Sarin, "Predicting utility under satiation and habit formation," Management Science, vol. 56, no. 2, pp. 286-301, 2010.

[14] M. Bertino, G. K. Beauchamp, and K. Engelman, "Increasing dietary salt alters salt taste preference," Physiology and Behavior, vol. 38, no. 2, pp. 203-213, 1986.

[15] K. K. Desai and M. Trivedi, "Do consumer perceptions matter in measuring choice variety and variety seeking?" Journal of Business Research, vol. 67, no. 1, pp. 2786-2792, 2014.

[16] P. B. Seetharaman and H. Che, "Price competition in markets with consumer variety seeking," Marketing Science, vol. 28, no. 3, pp. 516-525, 2009.

[17] L. Wathieu, "Habits and the anomalies in intertemporal choice," Management Science, vol. 43, no. 11, pp. 1552-1563, 1997.

[18] T. M. O. Alejandro, "Price competition in mixed strategies in markets with habit formation," EconoQuantum, vol. 7, no. 1, pp. 67-93, 2010.

[19] R. Chetty and A. Szeidl, "Consumption Commitments and Habit Formation," The Econometric Society, vol. 84, no. 2, pp. 855-890, 2016.

[20] H. Hotelling, "Stability in competition," The Economic Journal, vol. 39, no. 153, pp. 41-57, 1929.

[21] P. Klemperer, "The competitiveness of markets with switching costs," The RAND Journal of Economics, vol. 18, no. 1, p. 138, 1987.

[22] R. Zeithammer and R. Thomadsen, "Vertical differentiation with variety-seeking consumers," Management Science, vol. 59, no. 2, pp. 390-401, 2013.

[23] B. Bubalo and A. A. Gaggero, "Low-cost carrier competition and airline service quality in Europe," Transport Policy, vol. 43, pp. 23-31, 2015.

[24] K. Cheng, H.-P. Chen, and J. Z.-H. Lee, "Competition behavior in service frequency for U.S. airlines," Service Business, vol. 9, no. 1, pp. 1-16, 2015.

[25] J. M. Villas-Boas, "Consumer Learning, Brand Loyalty, and Competition," Marketing Science, vol. 23, no. 1, pp. 134-172, 2004. 


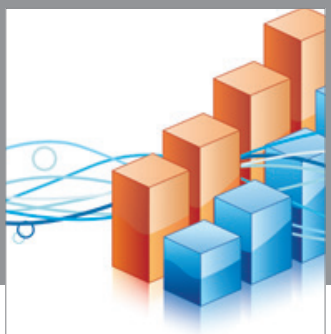

Advances in

Operations Research

vatem alat4

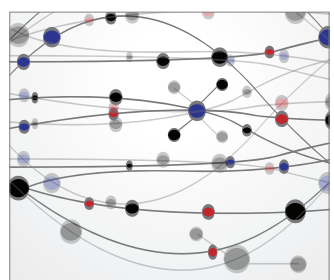

\section{The Scientific} World Journal
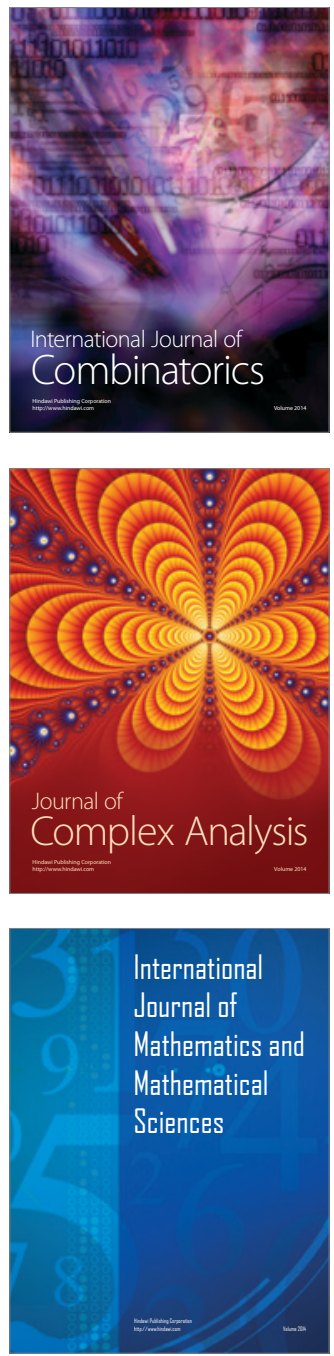
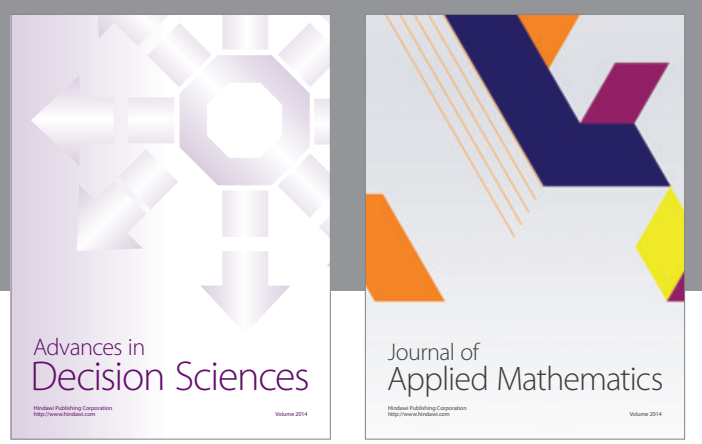

Algebra

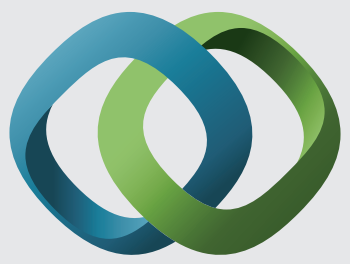

\section{Hindawi}

Submit your manuscripts at

https://www.hindawi.com
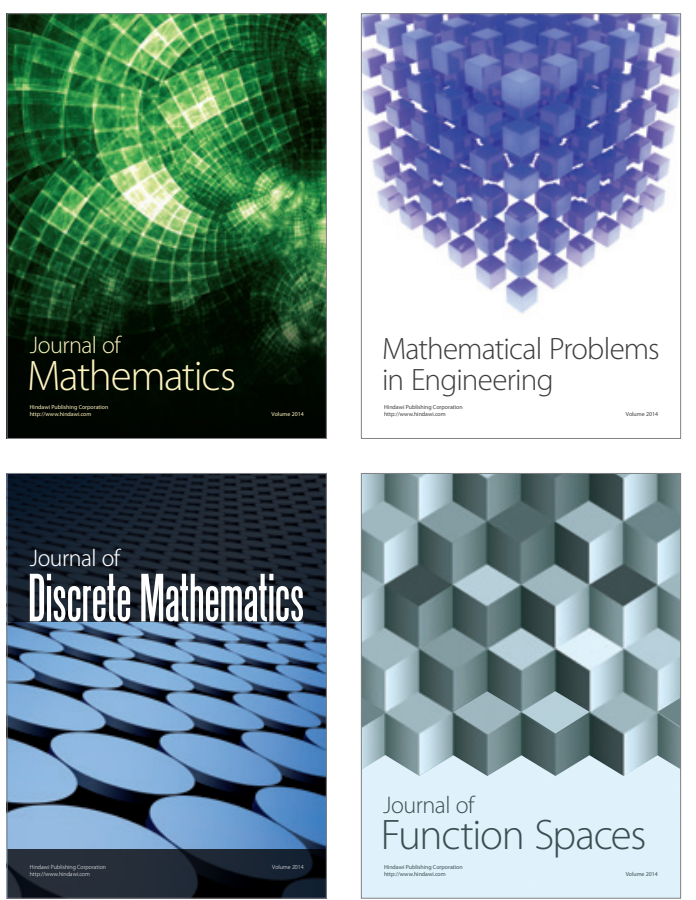

Mathematical Problems in Engineering
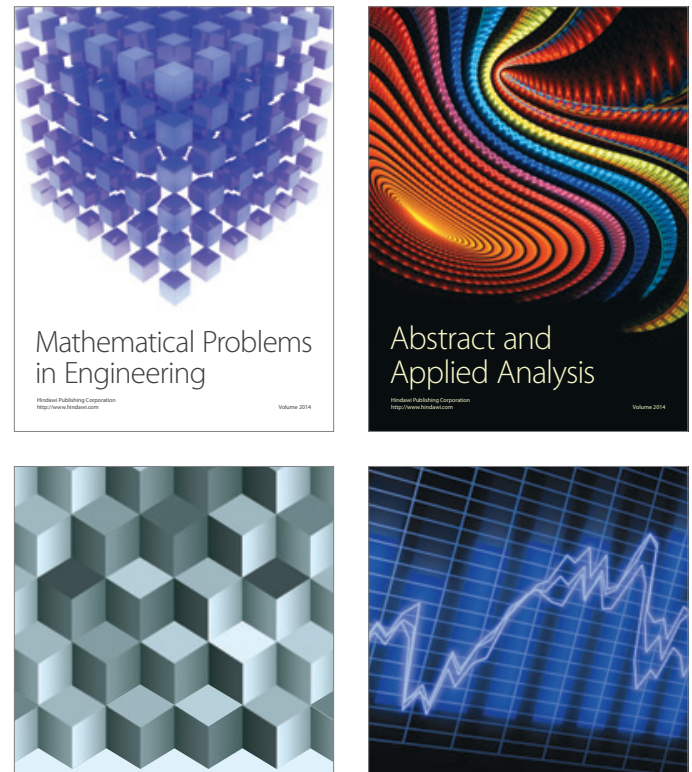

Journal of

Function Spaces

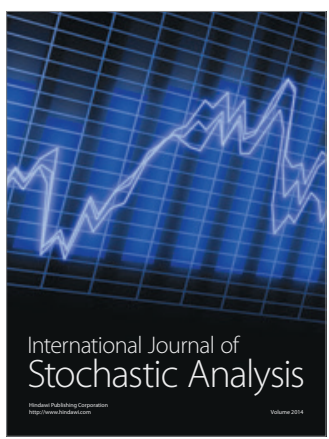

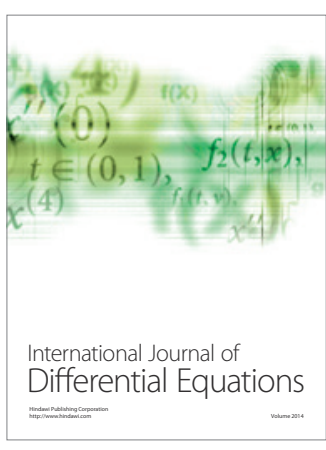
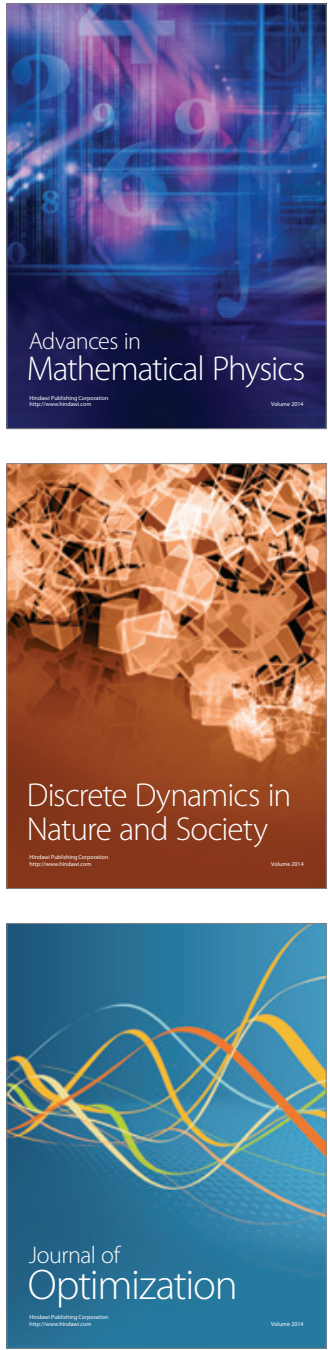